\title{
Level aktivitas fisik dan faktor risiko penyakit kardiovaskuler pada karyawan kantor di universitas
}

\author{
Febriani Fajar Ekawati *, Tri Winarti Rahayu, Hendrig Joko Prasetyo \\ Fakultas Keolahragaan, Universitas Sebelas Maret. Jl. Menteri Supeno, Manahan, Banjarsari, Kota \\ Surakarta, Jawa Tengah 57139, Indonesia \\ * Corresponding Author. Email: febriani@staff.uns.ac.id
}

Received: 18 June 2020; Revised: 3 September 2020; Accepted: 4 September 2020

\begin{abstract}
Abstrak: Noncommunicable Diseases (NCDs) merupakan salah satu penyebab kematian utama di dunia. Kurangnya aktivitas fisik dapat meningkatkan risiko penyakit ini. Meskipun telah banyak penelitian yang menyelidiki tentang hubungan aktivitas fisik dan faktor risiko penyakit kardiovaskuler, hanya terdapat beberapa penelitian di Indonesia yang menelaah tentang peran aktivitas fisik dalam perkembangan penyakit kardiovaskuler. Penelitian ini bertujuan untuk mendeskripsikan tingkat aktivitas fisik dan menyelidiki hubungannya dengan faktor risiko penyakit kardiovaskuler pada karyawan kantor di lingkungan Universitas Sebelas Maret (UNS). Penelitian ini menggunakan desain penelitian potong lintang, dengan jumlah sampel sebanyak 44 orang. Data level aktivitas fisik diperoleh dari International Physical Activity Questionnaire (IPAQ) sedangkan faktor-faktor risiko penyakit kardiovaskuler (gula darah, kolesterol, tekanan darah, lingkar pinggang, dan IMT) diukur dengan menggunakan alat ukur yang sesuai. Hasil penelitian menunjukkan bahwa level aktivitas fisik karyawan berkategori Rendah sebesar 6.82\%, Sedang sebesar $72.73 \%$, dan Tinggi sebesar 20.45\%. Berdasarkan uji Pearson Correlation, tekanan darah baik sistolik dan diastolik mempunyai hubungan yang signifikan dengan level aktivitas fisik. Tidak ada hubungan yang signifikan antara level aktivitas fisik dan faktor risiko lainnya dalam penelitian ini. Secara umum penelitian ini menunjukkan bahwa level aktivitas fisik karyawan di lingkungan UNS adalah berkategori sedang, dan tekanan darah mempunyai hubungan yang signifikan dengan aktivitas fisik.
\end{abstract}

Kata Kunci: aktivitas fisik, faktor risiko, penyakit kardiovaskuler, noncommunicable diseases

\section{Physical activity level and cardiovascular risk factors among university employees}

\begin{abstract}
Noncommunicable Diseases (NCDs) are one of the leading deaths in the world. Insufficiency of physical activity (PA) escalate the risk of NCDs. Although the reports of the studies investigating the relationship between $P A$ and cardiovascular risk factors are abundance, only a few studies in Indonesia examined the role of PA in the development of cardiovascular diseases. The aim of this study was to describe the level of PA and investigate the relationships between PA and cardiovascular risk factors among UNS employees. This was a cross sectional study with a sample of 44 university employees. PA level was assessed using IPAQ. Meanwhile cardiovascular risk factors such as plasma glucose, cholesterol, blood pressure, waist circumference, and BMI were measured using an appropriate tool for each measure. The results revealed that participants with low level of $P A(6.82 \%)$, moderate category $(72.73 \%)$, and high category (20.45\%). Pearson Correlation analysis showed blood pressure both systolic and diastolic had a significant association with PA level. There was no a significant association between PA level and others cardiovascular risk factors in this research. Generally, this study exhibited the level of PA among UNS employees in the moderate category, and blood pressure had a significant association with PA.
\end{abstract}

Keywords: physical activity, risk factor, cardiovascular disease, noncommunicable diseases

How to Cite: Ekawati, F., Rahayu, T., \& Prasetyo, H. (2020). Level aktifitas fisik dan faktor risiko penyakit kardiovaskuler pada karyawan kantor di universitas. Jurnal Keolahragaan, 8(2), 166-173. doi:https://doi.org/10.21831/jk.v8i2.32541 


\section{PENDAHULUAN}

Non-Communicable Diseases (NCDs) atau yang biasa disebut dengan penyakit tidak menular adalah kondisi medis atau suatu penyakit yang tidak disebabkan oleh infeksi tertentu. Meskipun tidak menular dari manusia ke manusia, NCDs merupakan penyebab utama kematian di dunia, yaitu sebesar $71 \%$ atau 41 juta orang per tahun (World Health Organisation, 2019). Terdapat empat tipe utama dari NCDs yaitu penyakit-penyakit kardiovaskuler, kanker, penyakit paru-paru kronis, dan diabetes. Lebih lanjut, dimana modifiable behaviours seperti merokok, kurang gerak, diet yang tidak sehat, dan mengonsumsi alkohol dapat meningkatkan risiko penyakit-penyakit tersebut (Forouzanfar et al., 2016). Menurut World Health Organization (2011), tiga per empat dari kematian global yang disebabkan oleh NCDs mengenai orang-orang di negara berkembang. Di Indonesia, peningkatan prevalensi NCDs didorong oleh tingginya angka obesitas yang merupakan faktor risiko dari hipertensi, penyakit jantung, kanker, dan diabetes (Brouwer \& Nugent, 2015). Sebuah hasil penelitian melaporkan bahwa Indonesia adalah negara yang penduduknya masuk dalam kategori kurang gerak (Althoff et al., 2017). Kondisi ini mungkin yang memicu tingginya prevalensi obesitas di Indonesia.

Penelitian dalam bidang lingkungan dan aktivitas fisik melaporkan bahwa kondisi lingkungan sekitar pada saat ini mempunyai peran dalam memengaruhi mempengaruhi prevalensi obesitas (Sallis et al., 2012). Desain pembangunan tempat umum dan perkantoran yang modern mendorong manusia untuk meminimalkan aktivitas otot dan gerakan manusia. Contohnya, penggantian fungsi tangga dengan alat bermesin seperti eskalator dan elevator (lift) mempromosikan gaya hidup tidak aktif secara fisik. Tidak hanya faktor lingkungan, perkembangan teknologi dan modernisasi juga mempengaruhi penurunan partisipasi dalam beraktivitas fisik secara global (Ng \& Popkin, 2012). Di Amerika, para wanita cenderung $25 \%$ lebih banyak menghabiskan waktunya untuk menonton televisi dan mengoperasikan komputer daripada melakukan pekerjaan rumah tangga mereka (Archer et al., 2013). Selain faktor lingkungan dan kemajuan teknologi, kepemilikan mobil juga mempengaruhi kurangnya aktivitas fisik seseorang (Shoham et al., 2015). Penurunan partisipasi aktivitas fisik yang disebabkan oleh perkembangan teknologi ini diprediksi akan terus berlanjut (Ng \& Popkin, 2012). Penelitian yang dilakukan di negara maju menunjukkan bahwa sampai dengan tahun 2030 orang-orang dewasa hanya akan menghabiskan energi harian mereka lebih rendah dari pedoman yang sudah ada yaitu hanya sebesar 126 Metabolic Equivalent of Task (METs) jam per minggu (Ng \& Popkin, 2012).

Tidak diragukan lagi bahwa melakukan aktivitas fisik secara teratur dapat mengurangi perkembangan dari NCDs termasuk penyakit kardiovaskular, diabetes melitus tipe II, obesitas, dan penyakit Alzheimer (Reiner et al., 2013). Lebih lanjut, aktivitas fisik mempunyai hubungan yang signifikan dengan komponen-komponen sindrom metabolik seperti lingkar pinggang, gula darah puasa, trigliserid, kolesterol, dan tekanan darah baik sistolik dan diastolik (Sheikholeslami et al., 2018). Meskipun hasilhasil penelitian menunjukkan manfaat yang positif dari melakukan aktivitas fisik, tetapi data menunjukkan bahwa kurangnya motivasi, tidak ada waktu, dan kurangnya pengetahuan merupakan halangan umum pada orang dewasa untuk melakukan aktivitas fisik (Herazo-Beltrán et al., 2017). Dalam hal kurangnya informasi, individu yang kurang gerak karena kebanyakan duduk seperti para karyawan kantor di universitas, mengabaikan lingkungan sekitar mereka sebagai tempat yang cocok untuk melakukan aktivitas fisik yang mudah dan tanpa mengeluarkan biaya yang besar. Sebuah penelitian yang dilakukan oleh Ryan et al., (2011) menemukan bahwa para karyawan kantor menghabiskan 66\% waktu kerja mereka hanya duduk di belakang meja. Lebih lanjut, 25\% dari mereka menghabiskan waktu 55 menit dalam satu periode duduknya. Di Indonesia khususnya di Jakarta, para pekerja kantor rata-rata menghabiskan waktu mereka untuk berperilaku sedentari adalah selama 8 jam per hari, yang dimungkinkan ini terjadi saat mereka berada di area kantor (Abadini \& Wuryaningsih, 2018). Perilaku kurang aktif secara fisik pada karyawan kantor ini juga dipengaruhi oleh panjangnya durasi waktu bekerja mereka (Kirk \& Rhodes, 2011). Sementara WHO menyarankan bahwa setiap individu dewasa harus melakukan aktivitas fisik selama 30 menit atau lebih aktivitas fisik dengan intensitas sedang tiap harinya dalam satu minggu, aktivitas para karyawan kantor tersebut masih jauh dari pedoman yang ada. Sebagai konsekuensinya, perilaku tersebut dapat meningkatkan risiko dari penyakit kardiovaskular, obesitas, dan diabetes (Chau et al., 2014).

Beberapa penelitian telah menyelidiki tentang hubungan aktivitas fisik dengan faktor-faktor risiko penyakit kardiovaskular di antara remaja, dewasa, dan lansia (Forrest et al., 2001; Kong et al., 2010; Martinez-Rueda et al., 2017; Oyeyemi \& Adeyemi, 2013). Indeks Masa Tubuh (IMT), lingkar pinggang, 
tekanan darah, profil lipid, gula darah pada umumnya mempunyai hubungan yang signifikan dengan aktivitas fisik. Di Indonesia, sampai saat ini, masih sedikit penelitian yang mengkaji tentang hubungan aktivitas fisik dengan faktor-faktor risiko penyakit kardiovaskular pada individu tanpa penyakit tertentu (dalam penelitian ini adalah para karyawan kantor di universitas). Di sisi lain, penelitian dengan sampel pasien dengan penyakit tertentu seperti Diabetes Melitus tipe 2 dan jantung koroner telah banyak dilakukan dan hubungan antara keduanya sangat jelas (Kusumawardhana, 2016; Nurayati \& Adriani, 2017; Setyaji et al., 2018). Dengan menggunakan International Physical Activity Questionnaire (IPAQ), penelitian ini bertujuan untuk mengetahui level aktivitas fisik di antara karyawan kantor di universitas. Selanjutnya dilihat hubungannya dengan beberapa faktor risiko penyakit kardiovaskular. Hasil dari penelitian ini diharapkan dapat membantu peneliti memberikan dasar yang kuat untuk mengembangkan intervensi dengan target peningkatan aktivitas fisik di lingkungan tempat kerja.

\section{METODE}

Penelitian ini merupakan penelitian potong lintang (cross sectional study) dengan tujuan untuk mengetahui level aktivitas fisik dan hubungannya dengan faktor-faktor risiko penyakit kardiovaskular. Subjek dalam penelitian ini adalah karyawan kantor Universitas Sebelas Maret (UNS) dengan kriteria sebagai berikut: merupakan karyawan universitas nonakademik dan tidak memiliki kecacatan yang menghambat berjalan secara mandiri. Pemilihan sampel dengan menggunakan purposive sampling, yaitu sebuah teknik non-random sampling dimana peneliti dalam mengambil sampel dengan cara menetapkan ciri-ciri khusus yang sesuai dengan tujuan penelitian, atau dengan kata lain dengan pertimbangan tertentu. Dalam penelitian ini, sampel diperoleh pada saat acara Kampus Sehat di UNS pada bulan November 2019. Partisipan datang ke tenda peneliti, kemudian mengisi lembar identitas untuk mengetahui bahwa partisipan adalah benar-benar karyawan universitas nonakademik yang berasal dari berbagai fakultas dan unit kerja. Setelah selesai pengambilan data, partisipan diberikan kartu sehat yang berisi tentang rangkuman hasil tes mereka sebagai ucapan terima kasih. Berdasarkan data lapangan, diperoleh 50 partisipan tetapi untuk proses analisis data, hanya 44 partisipan yang masuk kriteria. Enam yang gugur karena tidak mengisi angket (IPAQ) secara lengkap. Kelaikan etik diperoleh dari Komite Etik Penelitian Kesehatan, Fakultas Kedokteran, Universitas Muhammadiyah Surakarta.

Untuk mengukur tingat aktivitas fisik digunakan IPAQ dalam bahasa Bahasa Indonesia (Hastuti, 2013). Kuisioner ini memperkirakan aktivitas fisik berkategori sedang dan berat yang dilakukan selama tujuh hari terakhir, yang meliputi aktivitas pada saat bekerja, sebagai bagian dari pekerjaan rumah dan berkebun, perjalanan dari satu tempat ke tempat lain, dan pada saat waktu luang, rekreasi, melakukan olahraga. Hasil perhitungan dari IPAQ membedakan tingkat aktivitas dalam tiga kategori yaitu rendah, sedang, dan tinggi. Penjumlahan skor tersebut disampaikan dalam satuan METs untuk jenis aktivitas tertentu di seluruh domain (Fan et al., 2005; IPAQ Research Committee, 2005). Dalam mengisi kuisioner, partisipan dipandu oleh tim peneliti. Untuk mendapatkan data faktor-faktor risiko penyakit kardiovaskular dilakukan pengukuran sebagai berikut: tekanan darah diukur dengan menggunakan pengukur tekanan darah otomatis merek Omron seri HEM-8712 dengan pengulangan tiga kali dengan jeda waktu tiap pengukuran tiga menit (diambil rata-rata), kolesterol dan gula darah sewaktu diukur dengan menggunakan capillary blood test merek Easy Touch, lingkar pinggang diukur dengan menggunakan body tape measure caliper, dan berat badan serta IMB diukur dengan menggunakan Omron Karada Scan Body Composition Monitor HBF-375.

Teknik analisis data yang digunakan dalam penelitian ini adalah menggunakan statistik deskriptif dan untuk menilai hubungan antara aktivitas fisik dan faktor risiko penyakit kardiovaskular digunakan analisis regresi berganda.

\section{HASIL DAN PEMBAHASAN}

Karakteristik partisipan dalam penelitian ini meliputi jenis kelamin dan usia. Tabel 1 menunjukkan distribusi partisipan yang terlibat dalam penelitian ini, dimana partisipan paling banyak adalah pada rentang usia 30 - 49 tahun yaitu sebesar 34.09\%. Hal ini selaras dengan hasil survei 2018 Asia Pacific Healthy Ageing Survey yang dilakukan oleh salah satu produk nutrisi di Indonesia yang menyatakan bahwa rata-rata masyarakat di Asia Pasifik mulai sadar akan pentingnya pola hidup sehat adalah pada rentang usia 40 - 45 tahun (Sulaiman \& Nodia, 2018). Pada umumnya, jika ada pemeriksaan kesehatan, individu dengan rentang usia tersebut akan lebih tertarik untuk berpartisipasi. Untuk distribusi jenis 
kelamin, responden karyawan nonakademik di kampus UNS ini sebagian besar berjenis kelamin perempuan yaitu sebesar 54.55\%. Berdasarkan hasil survei pada pengunjung situs kesehatan meetdoctor.com, wanita merupakan pengunjung terbanyak untuk menanyakan tentang kesehatan mereka (Anna, 2014). Hal ini terjadi mungkin karena wanita lebih peduli dengan kesehatan dibandingkan dengan laki-laki.

Tabel 1. Karakteristik Partisipan Karyawan UNS Dilihat dari Jenis Kelamin dan Usia

\begin{tabular}{lcc}
\hline Karakteristik Partisipan & $\mathrm{N}$ & $\%$ \\
\hline Umur & 5 & \\
$20-29$ & 13 & 29.36 \\
$30-39$ & 15 & 34.09 \\
$40-49$ & 11 & 25.00 \\
$50-60$ & & \\
Jenis Kelamin & 20 & 45.45 \\
Laki-laki & 24 & 54.55 \\
Perempuan & \\
\hline
\end{tabular}

Tabel 2 menunjukkan bahwa 72.73\% responden karyawan kantor UNS mempunyai level aktivitas fisik pada kategori sedang (600 - 2999 MET - Menit/Minggu). Sesuai dengan informasi yang kami peroleh dari responden, aktivitas terbanyak dilakukan saat mereka berkegiatan di rumah seperti bersihbersih lantai dan jendela, serta mengangkat barang agak berat. Ditambah lagi, dengan adanya program Kampus Sehat di UNS, mungkin berpengaruh pada perilaku hidup sehat di antara diantara para karyawan.

Tabel 2. Distribusi Aktivitas Fisik Partisipan Karyawan UNS

\begin{tabular}{lcc}
\hline Aktivitas Fisik & $\mathrm{N}$ & $\%$ \\
\hline Rendah (<600 MET - Menit/Minggu) & 3 & 6.82 \\
Sedang (600 - 2999 MET - Menit/Minggu) & 32 & 72.73 \\
Tinggi ( $\geq 3000$ MET - Menit/Minggu) & 9 & 20.45 \\
\hline
\end{tabular}

Tabel 3. Nilai Pearson Correlation dan Probabilitas antara Aktivitas Fisik dan Faktor-Faktor Risiko Penyakit Kardiovaskular.

\begin{tabular}{lcl}
\hline \multicolumn{1}{c}{ Faktor-Faktor Risiko Kardiovaskuler } & $\mathrm{R}$ & $p$-value \\
\hline Indeks Masa Tubuh $\left(\mathrm{kg} \cdot \mathrm{m}^{-2}\right)$ &. .184 & .116 \\
Kolesterol $(\mathrm{mg} / \mathrm{dL})$ & .011 & .472 \\
Gula Darah $(\mathrm{mg} / \mathrm{dl})$ & .128 & .205 \\
Lingkar Perut $(\mathrm{cm})$ & -.237 & .061 \\
Tekanan Darah Sistolik $(\mathrm{mmHg})$ & .461 & $.001^{* *}$ \\
Tekanan Darah Diastolik $(\mathrm{mmHg})$ & .322 & $.017^{*}$ \\
\hline
\end{tabular}

$* p<0.05 \quad * * p<0.01 \quad * * * p<0.001$

Tabel 3 menunjukkan hasil uji Pearson Correlation antara aktivitas fisik dan faktor-faktor risiko penyakit kardiovaskuler dalam penelitian ini. Hasil uji statistik menunjukkan bahwa ada hubungan yang signifikan antara tingkat aktivitas fisik dengan tekanan darah sistolik dan tekanan darah diastolik. Hal ini selaras dengan hasil penelitian di Nigeria yang menyatakan bahwa level aktivitas fisik masyarakat perkotaan berhubungan dengan kedua jenis tekanan darah (Oyeyemi \& Adeyemi, 2013). Meskipun telah terbukti bahwa aktivitas fisik merupakan komponen penting dari lifestyle therapy untuk pencegahan dan pengobatan gangguan tekanan darah, untuk pelaksanaannya masih perlu diperhatikan dosis latihan yang diberikan. Sebuah penelitian di Yunani yang melihat hubungan antara level aktivitas fisik dengan tekanan darah pada kelompok remaja menemukan bahwa kelompok anak yang mempunyai aktivitas fisik tinggi mempunyai tekanan darah sistolik yang tinggi pula (Tsioufis et al., 2011). Lebih lanjut, para peneliti tersebut menyarankan bahwa aktivitas fisik yang dilakukan secara reguler hendaknya dilakukan pada intensitas sedang untuk menghindari kenaikan tekanan darah sistolik. Salah satu contoh aktivitas fisik dengan intensitas sedang yang dapat diterapkan sebagai gaya hidup aktif sehari-hari adalah aktivitas jalan kaki (walking). Hasil penelitian menunjukkan bahwa terjadi penurunan level tekanan darah sistolik, denyut jantung, lingkar pinggang, dan IMT ketika menjalankan program peningkatan jumlah langkah atau step count (Yuenyongchaiwat et al., 2017). Hal ini juga sejalan dengan petunjuk aktivitas fisik dari WHO. Anak-anak dan remaja usia 5 - 17 tahun disarankan untuk melakukan aktivitas 
fisik paling sedikit 60 menit per hari dengan intensitas sedang sampai ke intensitas tinggi (World Health Organization, 2011). Dimana, jenis aktivitas yang lebih banyak dilakukan adalah aktivitas fisik tipe aerobik, untuk aktivitas fisik dengan intensitas tinggi dapat dilakukan tiga kali dalam satu minggu yaitu berupa latihan yang dapat meningkatkan kekuatan otot dan tulang. Selain menunjukkan efek secara langsung pada tingkat kesehatan seseorang, tinjauan aktivitas fisik dari faktor sosial juga memperlihatkan manfaat melakukan aktivitas fisik secara rutin. Berdasarkan hasil penelitian, remaja yang lebih banyak menghabiskan hari-harinya dengan melakukan kegiatan yang berkaitan dengan hobinya mempunyai hubungan yang positif dengan level tekanan darah dan juga ukuran badannya (Tsioufis et al., 2011). Dalam penelitian ini, hasil pengujian statistik juga menunjukkan hubungan yang signifikan antara tekanan darah sistolik dan level aktivitas fisik, yaitu sebesar $21.3 \%$, besar korelasi antarkeduanya yaitu 0.46. Aktivitas fisik mungkin mempunyai peranan penting dalam pencegahan penyakit hipertensi, namun hubungan dosisnya dengan respons tekanan darah pada populasi remaja masih belum pasti atau masih menjadi perdebatan para ahli di bidang ini. Berbeda dengan kelompok remaja, semakin tinggi level aktivitas fisik seseorang pada kelompok usia dewasa mempunyai hubungan yang positif dengan faktor-faktor yang berhubungan dengan kesehatan seperti trigliserida, total kolesterol, dan tekanan darah diastolik Chung et al., (2017). Dengan demikian, masih diperlukan penelitian yang mendalam tentang dosis aktivitas fisik dan pengaruhnya pada faktor-faktor yang berkaitan dengan level kesehatan di seluruh tingkatan populasi.

Level aktivitas fisik tidak selalu mempunyai hubungan yang signifikan dengan faktor-faktor risiko penyakit kardiovaskular. Hal ini bergantung pada usia dan jenis kelamin. Sebuah penelitian di Korea menjelaskan bahwa pada kelompok wanita dewasa dan lanjut usia, level aktivitas fisik tidak berhubungan dengan faktor-faktor yang berhubungan dengan kondisi kesehatan, tetapi mempunyai pengaruh pada berat badan, lingkar pinggang, IMT dan usia (Chung et al., 2017). Berbeda dengan hasil penelitian ini, selain tidak ada hubungan yang signifikan antara tingkat aktivitas fisik dengan kondisi kolesterol, gula darah, uji regresi berganda juga menunjukkan bahwa lingkar perut, berat badan dan indeks masa tubuh tidak dipengaruhi oleh level aktivitas fisik pada karyawan kantor. Hasil penelitian ini juga bertentangan dengan penelitian terdahulu dengan sampel kelompok individu dewasa, level aktivitas fisik mempunyai korelasi yang signifikan dengan berat badan, IMT, dan lingkar pinggang (Oyeyemi \& Adeyemi, 2013; Sheikholeslami et al., 2018). Ukuran berat badan dan IMT bukan merupakan indikator terbaik untuk melihat komposisi tubuh, karena hasil ukurannya tidak memperlihatkan seberapa banyak lemak, otot, dan tulang. Sehingga, kondisi berat badan berlebih dan IMT yag tinggi tidak selalu mencerminkan risiko kesehatan secara langsung.

Dalam penelitian ini juga tidak memperlihatkan adanya hubungan antara level aktivitas fisik dengan kondisi gula darah para karyawan. Hal ini bertolak belakang dengan hasil penelitian sebelumnya. Hasil penelitian yang melihat hubungan antara aktivitas fisik dengan gula darah puasa menunjukkan terdapat hubungan antara kedua variabel (Chung et al., 2017; Nurayati \& Adriani, 2017). Pengukuran gula darah dalam penelitian ini adalah gula darah sewaktu, bukan gula darah puasa, mungkin hal ini yang menyebabkan hasil penghitungan statitistiknya tidak ada hubungan yang signifikan. Selain itu, alat ukur gula darah yang digunakan mungkin juga mempengaruhi hasil penelitian. Penelitian ini tidak mengambil sampel darah vena, tetapi hanya mengambil sampel darah kapiler.

Selain tidak ada hubungan antara aktivitas fisik dengan gula darah, hasil penelitian ini juga tidak menunjukkan adanya hubungan aktivitas fisik dengan kondisi kolesterol para karyawan kantor. Pada penelitian terdahulu, aktivitas fisik juga tidak berhubungan dengan kondisi kolesterol pada sampel lakilaki, tetapi mempunyai pengaruh yang signifikan pada kondisi kolesterol perempuan (Chung et al., 2017). Pada penelitian ini tidak melakukan penghitungan terpisah antara laki-laki dan perempuan karena keterbatasan jumlah sampel yang ada. Penghitungan yang membedakan gender dan menambah jumlah sampel mungkin perlu dilakukan untuk memperjelas hasil penelitian ini.

\section{SIMPULAN}

Hasil analisis data menunjukkan bahwa aktivitas fisik berhubungan dengan tekanan darah baik yang sistolik dan diastolik. Variabel faktor risiko penyakit kardiovaskuler lainnya seperti kondisi gula darah dan kolesterol, IMT, dan lingkar perut tidak menunjukkan adanya hubungan dengan aktivitas fisik. Penelitian ini menggunakan IPAQ untuk melihat level aktivitas fisik para partisipan. Kelemahan menggunakan angket ini adalah partisipan mengisi berdasarkan self-report, sehingga sulit untuk 
menentukan jenis, jumlah, dan intensitas aktivitas fisik yang tepat yang berhubungan dengan faktorfaktor risiko penyakit kardiovaskuler yang diamati.

\section{DAFTAR PUSTAKA}

Abadini, D., \& Wuryaningsih, C. E. (2018). Determinan aktivitas fisik orang dewasa pekerja kantoran di Jakarta tahun 2018. Jurnal Promosi Kesehatan Indonesia, 14(1), 15. https://doi.org/10.14710/jpki.14.1.15-28

Althoff, T., Sosič, R., Hicks, J. L., King, A. C., Delp, S. L., \& Leskovec, J. (2017). Large-scale physical activity data reveal worldwide activity inequality. Nature, 547(7663), 336-339. https://doi.org/10.1038/nature23018

Anna, L. K. (2014). Wanita memang lebih peduli kesehatan. Kompas.Com. https://lifestyle.kompas.com/read/2014/11/12/070000423/Wanita.Memang.Lebih.Peduli.Keseha $\tan$

Archer, E., Shook, R. P., Thomas, D. M., Church, T. S., Katzmarzyk, P. T., Hébert, J. R., McIver, K. L., Hand, G. A., Lavie, C. J., \& Blair, S. N. (2013). 45-year trends in women's use of time and household management energy expenditure. PLoS ONE, 8(2), e56620. https://doi.org/10.1371/journal.pone.0056620

Brouwer, E., \& Nugent, R. (2015). Indonesian perspectives: Non-communicable diseases. Post-2015 Consensus.

Chau, J. Y., Grunseit, A., Midthjell, K., Holmen, J., Holmen, T. L., Bauman, A. E., \& van der Ploeg, H. P. (2014). Cross-sectional associations of total sitting and leisure screen time with cardiometabolic risk in adults. Results from the HUNT Study, Norway. Journal of Science and Medicine in Sport, 17(1), 78-84. https://doi.org/10.1016/j.jsams.2013.03.004

Chung, N., Park, H.-Y., Park, M.-Y., Hwang, Y.-Y., Lee, C.-H., Han, J.-S., So, J., Kim, J., Park, J., \& Lim, K. (2017). Association of daily physical activity level with health-related factors by gender and age-specific differences among Korean adults based on the sixth (2014-2015) Korea National Health and Nutrition Examination Survey. Journal of Exercise Nutrition \& Biochemistry, 21(2), 30-38. https://doi.org/10.20463/jenb.2017.0026

Fan, M., Lyu, J., \& He, P. (2005). Chinese guidelines for data processing and analysis concerning the International Physical Activity Questionnaire. Zhonghua Liu Xing Bing Xue Za Zhi= Zhonghua Liuxingbingxue Zazhi, 35(8), 961-964. https://europepmc.org/article/med/25376692

Forouzanfar, M. H., Afshin, A., Alexander, L. T., Anderson, H. R., Bhutta, Z. A., Biryukov, S., Brauer, M., Burnett, R., Cercy, K., Charlson, F. J., Cohen, A. J., Dandona, L., Estep, K., Ferrari, A. J., Frostad, J. J., Fullman, N., Gething, P. W., Godwin, W. W., Griswold, M., ... Murray, C. J. L. (2016). Global, regional, and national comparative risk assessment of 79 behavioural, environmental and occupational, and metabolic risks or clusters of risks, 1990-2015: a systematic analysis for the Global Burden of Disease Study 2015. The Lancet, 388(10053), 1659-1724. https://doi.org/10.1016/S0140-6736(16)31679-8

Forrest, K. Y.-Z., Bunker, C. H., Kriska, A. M., Ukoli, F. A. M., Huston, S. L., \& Markovic, N. (2001). Physical activity and cardiovascular risk factors in a developing population. Medicine \& Science in Sports \& Exercise, 33(9), 1598-1604. https://doi.org/10.1097/00005768-20010900000025

Hastuti, J. (2013). Anthropometry and body composition of Indonesian adults: an evaluation of body image, eating behaviours, and physical activity [Queensland University of Technology]. https://eprints.qut.edu.au/61740/

Herazo-Beltrán, Y., Pinillos, Y., Vidarte, J., Crissien, E., Suarez, D., \& García, R. (2017). Predictors of perceived barriers to physical activity in the general adult population: a cross-sectional study. Brazilian Journal of Physical Therapy, 21(1), 44-50. https://doi.org/10.1016/j.bjpt.2016.04.003

IPAQ Research Committee. (2005). Guidelines for data processing and analysis of the International Physical Activity Questionnaire (IPAQ)-short and long forms. In IPAQ. https://ci.nii.ac.jp/naid/10030318551/ 
Kirk, M. A., \& Rhodes, R. E. (2011). Occupation correlates of adults' participation in leisure-time physical activity: A systematic review. American Journal of Preventive Medicine, 40(4), 476485. https://doi.org/10.1016/j.amepre.2010.12.015

Kong, A. P. S., Choi, K.-C., Li, A. M. C., Hui, S. S. C., Chan, M. H., Wing, Y., Ma, R. C. W., Lam, C. W. K., Lau, J. T. F., So, W. Y., Ko, G. T. C., \& Chan, J. C. N. (2010). Association between physical activity and cardiovascular risk in Chinese youth independent of age and pubertal stageg. BMC Public Health, 10(1), 303. https://doi.org/10.1186/1471-2458-10-303

Kusumawardhana, B. (2016). Menurunkan kadar glukosa darah penderita diabetes melitus tipe-2 melalui latihan aerobic low impact dan ritmis. Jendela Olahraga, 1 (1 Juli).

Martinez-Rueda, R., Alba-P, L., \& Gutíerrez-G, A. (2017). Physical activity and cardiovascular risk factors in elderly in rural Cundinamarca, Colombia. European Journal of Public Health, 27(suppl_3), 464-465. https://doi.org/10.1093/eurpub/ckx186.182

Ng, S. W., \& Popkin, B. M. (2012). Time use and physical activity: A shift away from movement across the globe. Obesity Reviews, 13(8), 659-680. https://doi.org/10.1111/j.1467789X.2011.00982.X

Nurayati, L., \& Adriani, M. (2017). Hubungan aktifitas fisik dengan kadar gula darah puasa penderita diabetes melitus tipe 2. Amerta Nutrition, 1(2), 80. https://doi.org/10.20473/amnt.v1i2.6229

Oyeyemi, A. L., \& Adeyemi, O. (2013). Relationship of physical activity to cardiovascular risk factors in an urban population of Nigerian adults. Archives of Public Health, 71(1), 1-9. https://doi.org/10.1186/0778-7367-71-6

Reiner, M., Niermann, C., Jekauc, D., \& Woll, A. (2013). Long-term health benefits of physical activity -- a systematic review of longitudinal studies. BMC Public Health, 13(1), 813. https://doi.org/10.1186/1471-2458-13-813

Ryan, C. G., Dall, P. M., Granat, M. H., \& Grant, P. M. (2011). Sitting patterns at work: objective measurement of adherence to current recommendations. Ergonomics, 54(6), 531-538. https://doi.org/10.1080/00140139.2011.570458

Sallis, J. F., Floyd, M. F., Rodríguez, D. A., \& Saelens, B. E. (2012). Role of built environments in physical activity, obesity, and cardiovascular disease. Circulation, 125(5), 729-737. https://doi.org/10.1161/CIRCULATIONAHA.110.969022

Setyaji, D. Y., Prabandari, Y. S., \& Gunawan, I. M. A. (2018). Aktivitas fisik dengan penyakit jantung koroner di Indonesia. Jurnal Gizi Klinik Indonesia, 14(3), 115. https://doi.org/10.22146/ijen.26502

Sheikholeslami, S., Ghanbarian, A., \& Azizi, F. (2018). The physical activity and non-communicable diseases risk factors: 20 years of the TLGS findings. International Journal of Endocrinology and Metabolism, In Press(In Press). https://doi.org/10.5812/ijem.84740

Shoham, D. A., Dugas, L. R., Bovet, P., Forrester, T. E., Lambert, E. V., Plange-Rhule, J., Schoeller, D. A., Brage, S., Ekelund, U., Durazo-Arvizu, R. A., Cooper, R. S., \& Luke, A. (2015). Association of car ownership and physical activity across the spectrum of human development: Modeling the Epidemiologic Transition Study (METS). BMC Public Health, 15(1), 173. https://doi.org/10.1186/s12889-015-1435-9

Sulaiman, M. R., \& Nodia, F. (2018). Survei: Orang Indonesia baru mulai hidup sehat di usia 40 tahun. Www.Suara.Com. https://www.suara.com/health/2018/10/30/172918/survei-orangindonesia-baru-mulai-hidup-sehat-di-usia-40-tahun

Tsioufis, C., Kyvelou, S., Tsiachris, D., Tolis, P., Hararis, G., Koufakis, N., Psaltopoulou, T., Panagiotakos, D., Kokkinos, P., \& Stefanadis, C. (2011). Relation between physical activity and blood pressure levels in young Greek adolescents: The Leontio Lyceum Study. The European Journal of Public Health, 21(1), 63-68. https://doi.org/10.1093/eurpub/ckq006

World Health Organisation. (2019). Noncommunicable diseases. https://www.who.int/newsroom/fact-sheets/detail/noncommunicable-diseases

World Health Organization. (2011). WHO Global recommendations on physical activity for health. World Health Organization, United Nations. 
Jurnal Keolahragaan 8 (2), 2020 - 173

Febriani Fajar Ekawati, Tri Winarti Rahayu, Hendrig Joko Prasetyo

Yuenyongchaiwat, K., Pipatsitipong, D., \& Sangprasert, P. (2017). Increasing walking steps daily can reduce blood pressure and diabetes in overweight participants. Diabetology International, 9(1), 75-79. https://doi.org/10.1007/s13340-017-0333-z 